\section{ARQUITECTURA Y FUNCIONALIDAD DEL MUSEO JULIO ROMERO DE TORRES DE CÓRDOBA EN LA DÉCADA DE LOS TREINTA}

\author{
ARCHITECTURE AND FUNCTIONALITY OF THE JULIO ROMERO DE TORRES MUSEUM IN \\ CORDOBA IN THE THIRTIES
}

ARCHITECTURE E FONCTIONNALITÉ DU MUSÉE JULIO ROMERO DE TORRES À CORDOUE DANS LES ANNÉES TRENTE

RESUMEN: El estudio de la arquitectura museística forma parte de los intereses de la Museología. Este trabajo pretende acercarnos al momento de creación del Museo Julio Romero de Torres de Córdoba, a través del estudio y análisis del proceso de configuración y transformación de su edificio en la década de 1930 con el objetivo principal de poner de manifiesto el complejo programa de ampliaciones y reformas llevados a cabo bajo la tutela del Museo Provincial de Bellas Artes de Córdoba.

PALABRAS CLAVE: Arquitectura; museo; Museo Julio Romero de Torres; Córdoba; museología; espacio arquitectónico.
ABSTRACT: The study of museum architecture is part of the interests of Museology. This work intends. The purpose of this work is to bring us closer to the creation of the Julio Romero de Torres Museum in Córdoba, through the study and analysis of the configuration process and transformation of its building in the thirties of the last century, being the main objective to highlight the complex program of expansions and renovations carried out under the supervision of the then, Provincial Museum of Fine Arts in Cordoba.

KEYWORDS: Architecture; museum; Museo Julio Romero de Torres; Cordoba; museology; architectural space.
RÉSUMÉ: L'étude de l'architecture des musées fait partie des intérêts de la muséologie. La fin de ce travail est d'aborder le moment de la création du Musée Julio Romero de Torres à Cordoue, à travers l'étude et l'analyse du processus de configuration et de transformation du bâtiment au début des années trente, avec l'objectif principal de mettre en évidence les et les rénovations effectuées sous la supervision du Musée de Beaux-Arts à Cordoue.

MOTS-CLÉS: Architecture; musée Musée Julio Romero de Torres; Cordoue; muséologie; espace architectonique. extensions de programmes complexes

GARCÍA RAMOS, María Dolores

Universidad de Córdoba (UCO)

Dpto. de H. $\underline{a}$ del Arte, Arqueología y Música Plaza del Cardenal Salazar, $3 \mathrm{~s} / \mathrm{n}$ 14071 Córdoba

mdgarcia@uco.es

ORCID ID: 0000-0002-1342-7017

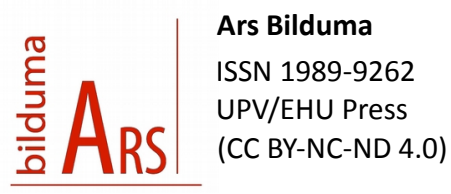

https://doi.org/10.1387/ars-bilduma.17963 BIBLID [(2018), 8; 177-199]

Recep.: 30/06/2017 Acept.: 24/10/2017 


\section{INTRODUCCIÓN}

En los años treinta del pasado siglo se configura en Córdoba el primer caso andaluz de museo de autor ${ }^{1}$, concretamente destinado a perpetuar la memoria de Julio Romero de Torres (1874-1930). El pintor cordobés pertenecía a una familia ligada a la vida cultural y artística de la ciudad: su padre, Rafael Romero Barros (1832-1895), ostentó desde 1862 el cargo de director del Museo de Pinturas - con posterioridad Provincial de Bellas Artes de Córdoba - a cuyo recinto se anexiona su vivienda familiar; de sus siete hermanos, Enrique (1872-1956) es el más destacado, siendo igualmente pintor, estuvo muy vinculado a la defensa y estudio del patrimonio histórico artístico de Andalucía, y sucedió en el cargo de director del Museo Provincial a su padre.

La repentina muerte de Julio Romero el 10 de mayo de 1930, en pleno éxito profesional, causó un gran revuelo, no solo en la ciudad sino también a nivel nacional, hecho que derivó en un derroche de homenajes públicos y populares. En este contexto situamos la gestión que del legado del pintor hizo la familia Romero de Torres, no queriéndose desprender de ninguno de sus bienes personales ni pictóricos con el objetivo de que este quedara ligado a Córdoba. Aprovechando la posición de Enrique Romero como director del Museo Provincial, se inician con una inusitada rapidez los trámites para que diecinueve meses después de su muerte, Córdoba tuviera un espacio en el que contemplar sus lienzos.

1 LÓPEZ RODRíGUEZ, J. R.: Historia de los museos de Andalucía. 1500-2000. Sevilla, Universidad de Sevilla, 2010. p. 335. En el II Congreso de Jóvenes Historiadores del Arte de la Universidad de Murcia (abril de 2016) se presentó una comunicación que ahonda en su clasificación museológica y en los valores que lo justifican. Para más información consúltese: GARCÍA RAMOS, Ma D.: "Consideraciones en torno a la definición tipológica del Museo Julio Romero de Torres de Córdoba", "Yngenio et arte": elogio, fama y fortuna de la memoria del artista. 2017 (En prensa).
El 23 de noviembre de 1931 fue la fecha elegida para la inauguración oficial del Museo. El local seleccionado se situaba en el recinto del antiguo Hospital de la Caridad de Nuestro Señor Jesucristo ${ }^{2}$, sito en la Plaza del Potro, lugar que tanto vínculo tiene con el desarrollo vital del pintor, la familia Romero de Torres y centro de la vida cultural de Córdoba. Concretamente, se instala en un pequeño pabellón construido en 1752 situado en el flanco Sur del conjunto, compartiendo instalaciones y bajo el amparo del Museo Provincial de Bellas Artes de Córdoba. En inicio este era propiedad de la Cofradía de la Caridad, que en este momento estaba ocupado por la Real Academia de Ciencias y Bellas Letras y Nobles Artes de Córdoba ${ }^{3}$.

Como se analiza en el presente estudio, este espacio será objeto de diversas intervenciones, dado que desde su inauguración se evidenciaban una serie de deficiencias que marcaron el carácter provisional de este primer proyecto. Así, tras una serie de reformas, de las que daremos cuenta más adelante, el 24 de mayo de 1936 vive la institución su segunda apertura, consecuencia de un proceso madurativo que terminó posicionándola como un referente del panorama museístico español de la década de 1930.

2 El antiguo Hospital de la Caridad fue fundado bajo el apoyo de los Reyes Católicos en el siglo XV. En la actualidad el edificio ostenta un uso museístico, estando ocupado en parte por las salas del Museo de Bellas Artes de Córdoba. Para un conocimiento evolutivo del edificio, vid: AGUAYO MARMOLEJO, M.: "Origen y construcción del Hospital de la Caridad de Nuestro Señor Jesucristo", La restauración de la fachada del antiguo Hospital de la Caridad. Museo de Bellas Artes de Córdoba. Sevilla, Junta de Andalucía, 2011, pp. 13-19.

3 LÓPEZ RODRÍGUEZ, J. R.: op. cit., p. 337. 


\section{LA RELACIÓN ENTRE ARQUITECTURA Y EL MUSEO}

La arquitectura de museos es uno de los elementos clave para la existencia de la institución museal tradicional, puede ser entendida como espectadora de la evolución y transformaciones de esta a lo largo de la historia, como una tipología arquitectónica o por su funcionalidad ${ }^{4}$ La museología es la ciencia que se encarga de su estudio que, siguiendo las teorías gestadas al amparo del Comité Internacional para la Museología (ICOFOM) ${ }^{5}$ del Consejo Internacional de Museos (ICOM), y como plantea el museólogo Vinos Sofka puede entenderse como la "ciencia o estudio de los museos, concebida en la actualidad como una investigación interdisciplinar, que está compuesta por otras ciencias, que les hacen converger hacia los museos, su sistema y sus características. Los métodos propios de cada una de estas ciencias están aplicados al objeto de investigación común, el museo" ${ }^{\prime}$, y se encarga, por tanto, del "conjunto de las tentativas de teorización o de reflexión crítica ligadas al espacio museal"7. Mientras que la Museografía se define según Lorente Lorente como "la técnica que expresa los conocimientos museológicos en el museo" y "que trata especialmente sobre la arquitectura y ordenamiento de las instalaciones científicas del museo" ${ }^{8}$. Es por ello que la arquitectura y el museo forman parte de su ámbito de estudio.

4 MONTANER, J. Mạ: Los museos de última generación. Barcelona, Gustavo Gili, 1986, p. 9.

5 El Comité Internacional para la Museología (ICOFOM) es un foro internacional destinado al debate, estudio, investigación y difusión del pensamiento museológico contemporáneo.

6 SOFKA, V.: Museologin i internationelli perspektiv. 1976 (texto inédito). Cita tomada de DESVALLÉES, A., y MAIRESSE, F.: Dictionnaire encyclopédique de muséologie. París, Armand Colin, 2002, p. 356

7 DESVAlLÉES, A., y MAIRESSE, F. (dirs.): Conceptos claves de museología. París, Armand Colin, 2010, p. 59

8 LORENTE LORENTE, J. P.: Manual de historia de la Museología. Gijón, Trea, 2012. p. 17.
Como venimos diciendo, la arquitectura es inherente a la institución museal, y como apuntan Desvallées y Mairesse, pudiendo definirse como "el arte de acondicionar o de construir un espacio destinado a alojar las funciones específicas de un museo y, además, particularmente, aquellas de exposición, de conservación preventiva, de estudio, de gestión y de acogida" ${ }^{\prime \prime}$. En base a esta definición, el edificio de un museo es el lugar en el que se expone y desarrolla la actividad museal. La arquitectura crea el espacio expositivo contenedor de objetos y un lugar en el que experimentar y desarrollar las técnicas de escenificación y museográficas.

También, la arquitectura puede entenderse como un elemento comunicador, que va más allá de la propia exposición, y en algunas ocasiones actúa como objeto de la narración, en el momento en el que esta se convierte en la materialización de un lugar. De este modo, no es solamente donde sucede el hecho museístico, sino que también otorga unas características semánticas a la práctica museográfica ${ }^{10}$.

La cuestión de las posibilidades de alojamiento del museo también es bastante recurrente, planteándose siempre la elección entre la creación de un inmueble de nueva planta o, por el contrario, reutilizar, previa adaptación, un edificio ya existente. Concretamente, la reutilización arquitectónica con usos museísticos se presenta como una práctica compleja. Como plantea Baztán Lacasa, la elección de edificios con "valor arquitectónico y simbólico", en algunas ocasiones viene a enriquecer la institución ${ }^{11}$.

9 DESVALLÉES, A., y MAIRESSE, F.: Dictionnaire... op. cit., p. 27.

10 MUÑOz COSME, A.: Los espacios de la mirada. Historia de la arquitectura de museos. Gijón, Trea, 2007, p. 291.

11 BAZTÁN LACASA, C.: "Museos en monumentos. Una pequeña historia y treinta ideas", Revista de Museología, no 17 (Arquitecturas para la mirada). A.E.M. Madrid, junio 1999, pp. 25-27. 
El estudio de la arquitectura de museos puede abordarse igualmente desde una lectura historiográfica, ya que el origen e historia de los museos $^{12}$, ámbito de la Museología, también puede estar ligado a un edificio. Es por ello que el fin de este estudio es el de acercarnos a los orígenes del Museo Julio Romero de Torres de Córdoba a través del estudio y análisis de edificio que lo acoge, formado desde la reutilización y fusión de varios inmueble. Para ello, es inexcusable conocer cómo se ha ido configurando espacial, estilística y volumétricamente el mismo; y su incidencia en su entorno urbanístico. Por tanto, es necesario reconstruir todo el proceso de transformación habido en el inmueble hasta el momento de la apertura de las nuevas salas, así como detallar todas las intervenciones realizadas a posteriori, durante los años treinta, destinadas a la consolidación del mismo.

\section{EL PROYECTO ARQUITECTÓNICO}

Como decíamos, el Museo Julio Romero de Torres nace como una sala del Museo Provincial de Bellas Artes de Córdoba. Esta relación viene impuesta por una dependencia administrativa, al ser el primero un espacio gestionado por del segundo; y espacial, al compartir ambos el complejo del antiguo Hospital de la Caridad ${ }^{13}$.

Además, el conjunto museístico que nos ocupa va a tener un papel muy destacado en la configuración del entorno urbano en el que se emplaza, la Plaza del Potro, lugar destacado en la ciudad desde la fundación del Hospital en $1493^{14}$ y que va ser objeto de varios cambios que afectarán a su

12 MAIRESSE, F.: “¿Ha terminado la historia de la museología?”, ICOFOM Study Series, 35, 2006, p. 94

13 LÓPEZ RODRÍGUEZ, J. R.: Ibídem.

14 AGUAYO MARMOLEJO, M.: op. cit., p. 13. articulación. Concretamente debemos referir para nuestro estudio aquellos que se sucedieron desde 1915 hasta 1934 y que afectaron al flanco Este de la plaza. En estos años se acometieron una serie de actuaciones de adecentamiento, remodelación y rehabilitación arquitectónica en los portales 1, 3 y 5 encaminadas a dignificar y a adaptar a nuevos usos la sede de la institución. Los cambios, como no podía ser de otro modo, marcaron considerablemente la fisionomía del espacio urbano, incorporando al paisaje nuevos hitos arquitectónicos de carácter histórico, artístico y cultural.

En este contexto, la plaza fue declarada Monumento arquitectónicoartístico mediante una Real Orden de 14 de junio de 1924. Junto con la Mezquita de Córdoba, fue el primer monumento catalogado de la ciudad. Esto supone que el entorno del entonces Museo Provincial gozaba de un fuerte reconocimiento a nivel nacional y que se activaron todos los mecanismos que permitía la legislación vigente en este momento para protegerlo por los valores histórico-artísticos que albergaba ${ }^{15}$.

En lo que sigue vamos a tratar de reconstruir siguiendo un hilo cronológico las intervenciones realizadas en este lugar, incidiendo en las aportaciones funcionales y estéticas.

15 La resolución contempla varios elementos de interés: "el conjunto de la Plaza del Potro, de la ciudad de Córdoba, integrado por la portada del antiguo Real Hospital de la Caridad de Nuestro Señor Jesucristo, hoy Museo Provincial de Bellas Artes; la fuente que decora la plaza; la posada llamada "del Potro", que lleva el número 13, y las casas señaladas con los números 5 y 7 , de dicha plaza, bellos ejemplares arquitectónicos del siglo XVI y lugar típico de la ciudad de Córdoba, cuya conservación se impone". Al año siguiente, la protección será ampliada con la inclusión del monumento al Arcángel San Rafael levantado en el siglo XVIII. Real Orden de 14 de junio de 1924, de declaración de Monumento arquitectónico-artístico el conjunto de la Plaza del Potro, de la ciudad de Córdoba; y Real Orden de 30 de junio de 1925, de ampliación en el sentido que se indica la Real orden de 14 de Junio de 1924, que declaró Monumento arquitectónicoartístico el conjunto de la Plaza del Potro, sita en Córdoba. 


\subsection{Los orígenes del edificio}

Para abordar el análisis de la configuración del espacio arquitectónico destinado a acoger las nuevas salas del Museo Julio Romero de Torres tenemos que partir de 1915, año en que Enrique Romero de Torres comienza una serie de acciones encaminadas a dignificar y a paliar el deterioro del inmueble de la institución que dirigía ${ }^{16}$.

Las actuaciones se iniciaron en 1916 con la cala de la fachada de la capilla del antiguo Hospital que abría al lado Este de la plaza. El resultado fue el descubrimiento de un pórtico medieval oculto desde principios del siglo XIX por un falso muro encalado. Seguidamente, en 1917 se procedió a la restauración del hallazgo con el objetivo de integrarlo en el entramado urbanístico ${ }^{17}$.

El encargado del proyecto fue Ricardo Velázquez Bosco, arquitecto que incorporaba una dilatada experiencia en la restauración de monumentos por todo el país. En Córdoba había intervenido en la restauración de la Mezquita de Córdoba de forma intermitente desde 1887 hasta 1918, y de 1910 a 1923 en el conjunto arqueológico de Madinat al-Zahra Azahara ${ }^{18}$.

16 El antiguo Hospital de la Caridad actuaba como sede del Museo de Pinturas y del Museo Arqueológico desde 1862, bajo la titularidad de la Diputación Provincial de Córdoba. Posteriormente, en 1865 su uso se amplió hasta 1881 al de biblioteca; en 1866 se instaló aquí la Escuela Provincial de Bellas Artes; y en 1917 se desalojan las piezas de arqueología para iniciar un periplo por varias sedes hasta que en 1920 ocupan definitivamente el Palacio de los Páez, separándose definitivamente las dos instituciones. LÓPEZ RODRÍGUEZ, J. R.: op. cit., pp. 264-265, 292-294.

17 PALENCIA CEREZO, J Mạ: "La puesta en valor de la fachada exterior del Museo de Bellas Artes de Córdoba (1915-1936)", La restauración de la fachada del antiguo Hospital de la Caridad. Museo de Bellas Artes de Córdoba. Córdoba, Junta de Andalucía, 2011, p. 27.

18 BALDELLOU SANTOLARIA, M.: Ricardo Velázquez Bosco. Catálogo de exposición. Madrid, Ministerio de Cultura, Centro Nacional de Exposiciones, 1990, pp. 21,118-156; 185-197.
Pero el plan no se limitó a la mera restauración del pórtico medieval, sino que previó la ampliación de la fachada hacia su lado derecho (hacia el Sur de la plaza) mediante la anexión de la casa contigua, la n. 3 de la plaza ${ }^{19}$, con el objetivo de crear una entrada digna para el Museo, al tiempo que ganaba espacios internos (Fig. 1). Para darle unidad estética, se ideó un diseño en estilo que buscaba fusionar la nueva entrada con el frente de la iglesia del Hospital, como veremos más adelante.

Velázquez Bosco se ocupó del proyecto desde 1917 hasta 1923 -año de su muerte-, cuando lo sustituye su ayudante el arquitecto Francisco Javier de Luque $^{20}$, asumiendo toda la labor de reforma del conjunto. En este momento, solo quedaban por finalizar algunos encargos menores y la ampliación del acceso y la fachada hacia el Sur de la plaza.

\subsection{Las intervenciones de Francisco Javier Luque en la plaza del Potro}

Desde la llegada del arquitecto Luque a Córdoba en $1923^{21}$, se irán sucediendo una serie de hechos que marcarán el desarrollo de un proyecto caracterizado por continuos cambios que vendrán a materializarse en la sede del nuevo Museo Julio Romero de Torres de Córdoba. Proceso que analizaremos en lo que sigue, prestando atención a los proyectos que se suceden para atender a las necesidades que se van generando.

19 El origen de la fachada del $n$. 1 de la Plaza del Potro se remonta a la segunda mitad de siglo XVIII. Sobre esta volaba la crujía de la casa n. 3, dando lugar a un acceso que posteriormente se será el recinto museístico mediante un pasadizo, concretamente al patio de entrada del actual Museo. Esta peculiaridad será objeto de las intervenciones que se realizarán en el inmueble. BALDELLOU SANTOLARIA, M.: op. cit., pp. 154-156; y PALENCIA CEREZO, J Ma: op. cit., p. 23.

20 BALDELLOU SANTOLARIA, M.: op. cit., p. 156

21 Ibídem. 


\subsubsection{La anexión de la casa número 3}

Lo que en un principio comenzó siendo una intervención destinada a poner en valor el pasado medieval de la fachada Este de la Plaza del Potro, como hemos visto, en 1924, Francisco Javier Luque, y a instancias de Enrique Romero de Torres, firmará los proyectos destinados a dignificar y a adecuar a su uso museístico, no solo la entrada del Museo Provincial, sino también sus instalaciones y los servicios que en estas se ofrecían. Así, en este año, la Dirección General de Bellas Artes del Ministerio de la Instrucción Pública decide atender la petición de Enrique Romero de "[...] dar a éste [Museo Provincial] la debida independencia, ampliándolo como corresponde para la colocación de obras de arte, y completar a la vez la fachada artística descubierta y restaurada, que decora el fondo de la plaza de Cervantes ${ }^{22}$, y antigua del Potro y da acceso al Museo" ${ }^{23}$. Para ello propone la compra de una casa de corte tradicional aledaña que pisaba la entrada del Museo, la n. 3 de la Plaza del Potro. La adquisición por parte del Ministerio de la Instrucción Pública se autoriza por Real Decreto de 2 de junio de $1925^{24}$, y se hace efectiva el 6 de agosto de ese mismo año, mediante la firma del contrato de compra-venta, entre Antonio Márquez Hidalgo, como propietario, y Enrique Romero de Torres, en representación del Estado ${ }^{25}$. El inmueble estaba construido en origen como vivienda de alquiler sobre

22 En estos momentos la Plaza del Potro estaba nombrada como de Cervantes, como homenaje de la cita que se hace en el Quijote de esta plaza, y cuyo recuerdo queda registrado en una placa situada en la fachada del Museo. Pese a esta nomenclatura oficial de la plaza, popularmente seguía siendo conocida como del Potro.

23 Archivo del Museo de Bellas Artes de Córdoba (en adelante AMBACO). c. 3, leg. 13. Carta de la Dirección General de Bellas Artes. Construcciones y monumentos al Delegado Regio de Bellas Artes de Córdoba, firmada en Madrid, a 27 de mayo de 1924.

24 Gaceta de Madrid. n. 153, 2 de junio de 1925, p. 1510.

25 AMBACO. c. 1. legajo 1. exp. 12. Referente a la adquisición de las casas $n .5$ de la del Potro y n. 3 de la misma para ampliación del Museo de Bellas Artes y de Julio Romero de Torres y obras de los mismos. Acta Notarial de la escritura de la casa n. 3 de la Plaza antiguos terrenos pertenecientes al antiguo Hospital de la Caridad y, como ya hemos indicado, su fachada quedaba contigua y sobrevolaba la entrada del Museo. Nos encontramos, pues, con dos exteriores que no guardaban consonancia alguna con el resto del edificio, ya que sus muros se mostraban encalados. A esto hay que añadir que sobre el dintel de la puerta de ingreso al conjunto - el primero de estos portales - se leían en unas sencillas letras de azulejo: "MUSEO PROVINCIAL DE BELLAS ARTES", como único indicativo de la institución. Es por ello, que la intención de Enrique Romero de Torres, con el encargo realizado a Francisco Javier Luque, era la de dignificar y resaltar la fachada sobre el resto de viviendas que abrían a este espacio urbano (Fig. 1).

Con la intención de atender a todas las necesidades expuestas, con fecha de 1 de marzo de 1926, Luque presenta el "Proyecto y presupuesto de demolición y reconstrucción de la casa contigua al Museo Provincial de Bellas Artes de Córdoba"26. Con este texto, se inician unas actuaciones encaminadas a insertar en las dependencias del Museo y a adaptar a usos museísticos el inmueble adquirido.

Para tal fin, se plantea una intervención que afectaría tanto al interior como al exterior, estableciendo criterios de actuación claramente diferenciados. Por un lado, el espacio interior de la casa adquirida se destina a crear nuevas zonas de administración. Esto demandaba una adaptación de la configuración espacial de toda la vivienda, así como el replanteamiento de las zonas de tránsito - escaleras y pasillos- y la sustitución de algunos materiales. $Y$ por otro lado, la intervención en el

del Potro, firmada por Enrique Romero de Torres por compra para el Estado, 15 de agosto de 1925.

26 Archivo General de la Administración (en adelante AGA). 31/4954. Proyecto $y$ presupuesto de demolición y reconstrucción de la casa contigua al Museo Provincial de Bellas Artes de Córdoba. 1 de marzo de 1926. 
exterior se centraba en cuestiones meramente estéticas, con las que se pretendía acomodar la fachada del inmueble nuevo a los valores estilísticos del pórtico del antiguo Hospital de la Caridad, creando de este modo una línea unitaria en el exterior de la Plaza del Potro.

A continuación pasamos a analizar los cambios que se produjeron en el espacio interior y que serán los que, años más tarde, acojan la colección de Julio Romero de Torres. Como adelantábamos, según la memoria del pro-

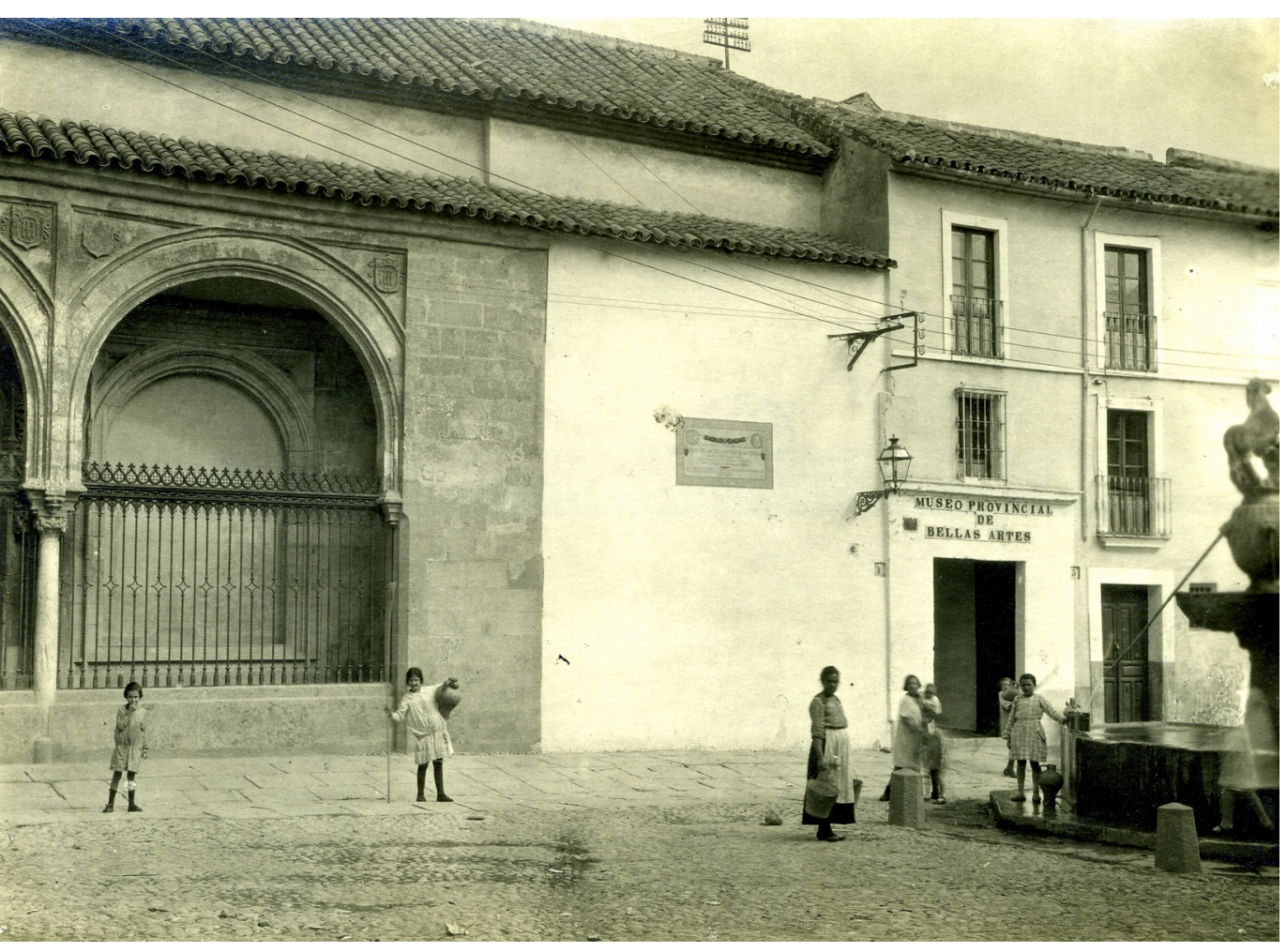

Fig. 1: Fachada del Museo Provincial de Bellas Artes con la fachada medieval descubierta y sin las intervenciones ejecutadas en los inmuebles 1 y 3 de la plaza del Potro. 1917-1923. Archivo Histórico Provincial de Córdoba. Fondo Fotográfico Romero de Torres (AHPCO. FFRT). F2278. Colección de la Junta de Andalucía. yecto, con la inclusión de este nuevo espacio se pretendían subsanar una serie de carencias detectadas por el director del Museo y que afectaban en gran medida al desarrollo de los servicios básicos del Museo.

Para crear dichos espacios se tuvo que alterar completamente la distribución interior de la casa. Se partía de una planta cuadrada, de 6,90 metros de ancho y 7,40 metros de profundidad. El piso bajo, en origen, estaba divido en dos zonas claramente diferenciadas: una, a la izquierda que ya era propiedad del Estado y que correspondía al corredor de acceso al patio principal del Museo, el cual no presentaba ningún nexo con la casa, y era de uso público; y otra, a la derecha, que pertenecía a la casa, con un pequeño portal como único acceso, con dos estancias y el arranque de la escalera en el lateral extremo derecho del solar (Fig. 2).

La intervención contemplaba el desmonte y demolición prácticamente integral de la casa n. 3, a excepción de la medianera que lindaba con el patio y los cimientos, alterando el número de estancias, parámetros y las conexiones espaciales. En el plano que el arquitecto adjunta a la memoria del proyecto, vemos claramente detalladas en amarillo las zonas que iban a ser suprimidas o sustituidas (Fig. 3 ) $^{27}$. Destaca la modificación del acceso a la finca, que en origen se realizaba desde la plaza y ahora se traslada a la medianera que comunica con el corredor de ingreso al Museo ${ }^{28}$ emplazando aquí dos puntos de acceso, uno al principio del pasillo y otro al final del mismo, quedando la antigua puerta de la casa convertida en una ventana. Esta planta se destina a la portería, un uso semipúblico, función que justifica la doble entrada, una para el contacto directo con los visitantes y otra de servicio.

27 AGA. 31/4954. Pliego de condiciones facultativas y económicas que, además de general de construcciones civiles aprobado por R. D. de 1908 y del de particulares para la subasta, regirá en las obras de reconstrucción, acceso y complemento de la fachada del Museo Provincial de Bellas Artes de Córdoba. 15 de diciembre de 1927.

28 El pasillo de entrada al Museo no sufre modificación alguna en este proyecto. 
Siguiendo la lectura del plano, las modificaciones proyectadas para el piso principal van a mantener una cierta concordancia con la baja: el interior se destina a despacho del director $y$ en el exterior se idean dos grandes ventanales. La segunda sigue el mismo patrón que la anterior, pero se reserva para un estudio y se abre al exterior mediante tres ventanales. Finalmente, la cubierta, que se adapta a las necesidades climáticas y a la estética de la arquitectura tradicional local al introducir una pequeña azotea y una techumbre sobre armadura de madera revestida con teja árabe. En definitiva, se proyectaron espacios para uso interno del Museo: el despacho de dirección, una portería, el archivo, dependencias para la manipulación de las colecciones y otros servicios. Pero también se tuvieron en cuenta cuestiones funcionales, tales como las relativas a las zonas de tránsito, la escalera, o de los espacios de higiene. También encontramos una intención de permanecer fieles a los valores estéticos de la construcción originaria, al adaptar las características constructivas y los materiales propios de la arquitectura local.

El segundo núcleo de actuación del proyecto de Luque se centra en la fachada exterior del edificio. Esta respondía a la intención de Enrique Romero de Torres antes referida de ennoblecer la entrada al Museo y convertir la pared este de la plaza del Potro en una única línea estética. Como no podía ser de otro modo, las pautas a seguir estaban marcadas por el edificio medieval, con cuya imagen debían armonizar las fachadas número 1 y 3.

En este sentido, hasta la fecha la fachada presentaba tres tipos de paramentos y de acabados diferentes. En la documentación gráfica que acompañaba al proyecto, el arquitecto municipal Carlos Sáez de Santamaría
MVSEO PROVINCIAL DE CORDOBA MODIFICACION DE SU ENTRADA DRINCIPAL

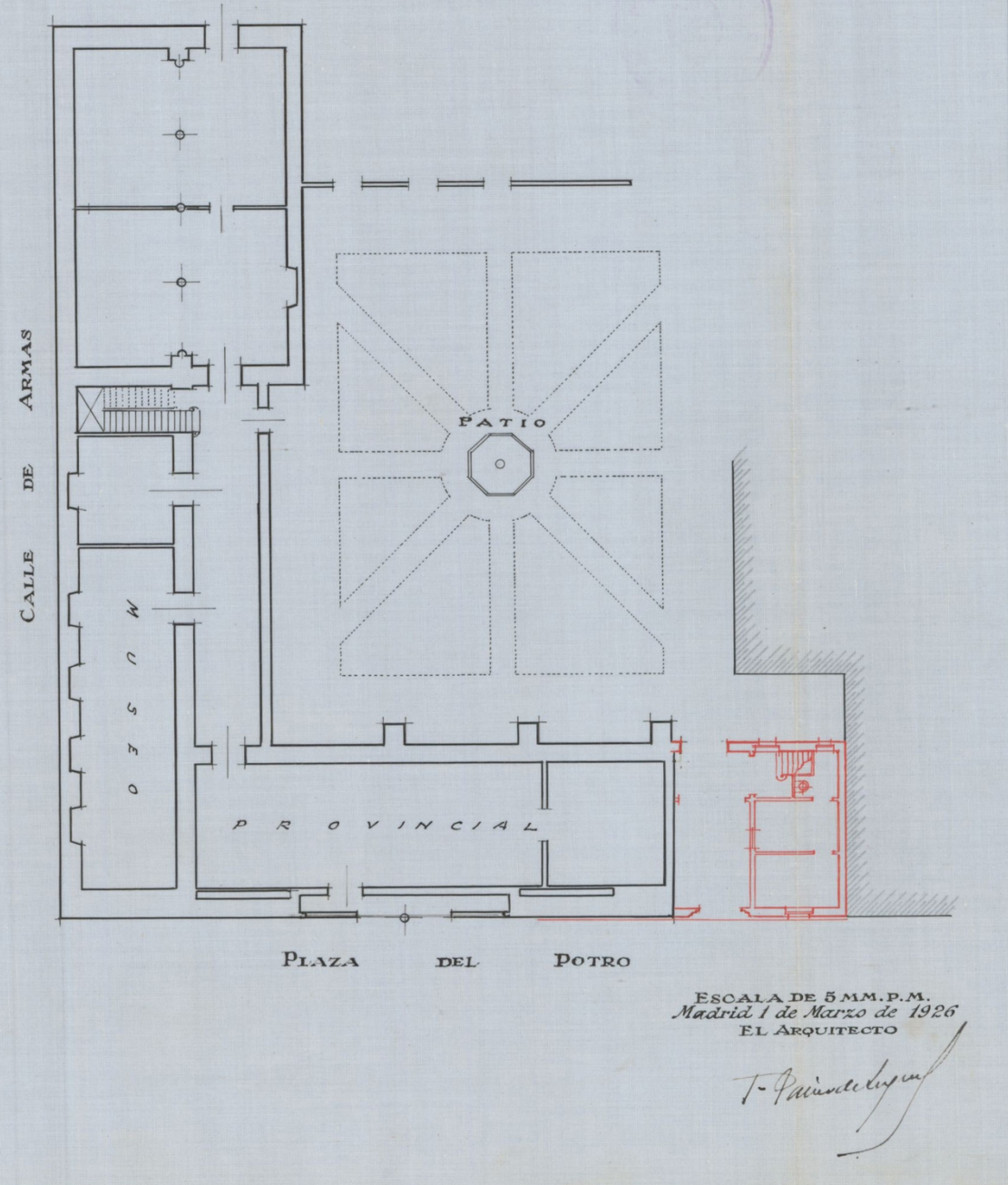

Fig. 2: Plano general del Museo Provincial de Bellas Artes en el que se marca en rojo la delimitación y distribución interior de la casa n. 3. Proyecto y presupuesto de demolición y reconstrucción de la casa contigua al Museo Provincial de Bellas Artes de Córdoba. 01/03/1926.

Ministerio de Educación, Cultura y Deporte (MECD), Archivo General de la Administracón (AGA) Fondo Ministerio de Educacón, Dirección General de Bellas Artes IDD (05)014.002, caja 31/4954 


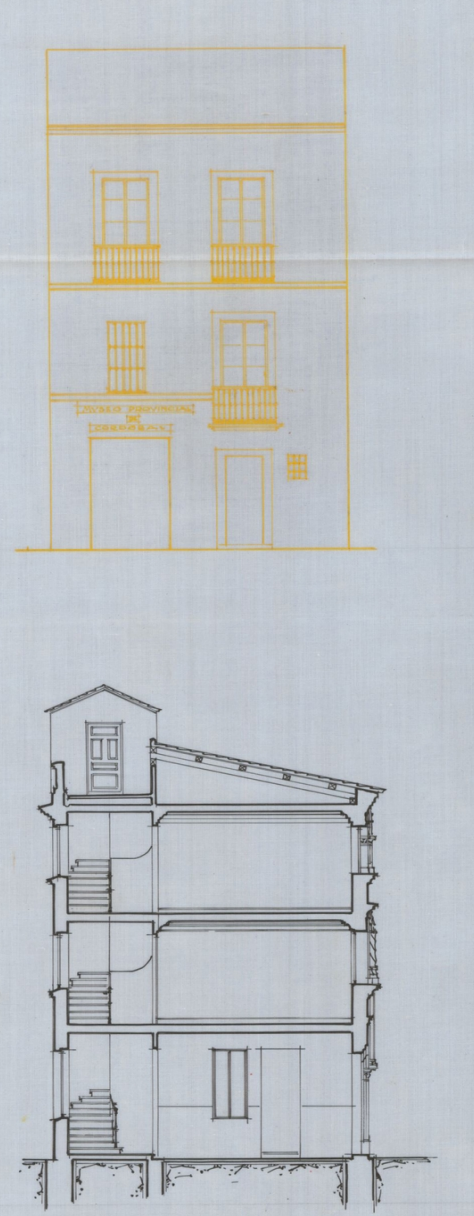

SECCIOIM $\triangle B$

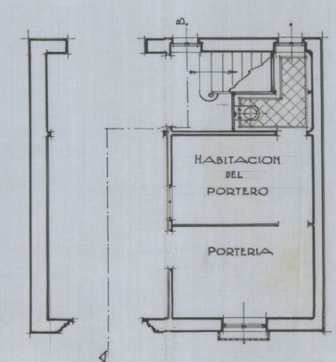

P. BANA

MVSEO PROVITCIAL DE CORDOBA

CASA ADOVIDIDA POR IL ESTADO PADA MODHTCAR JV EMTRADA

Escala de litroo $m$.
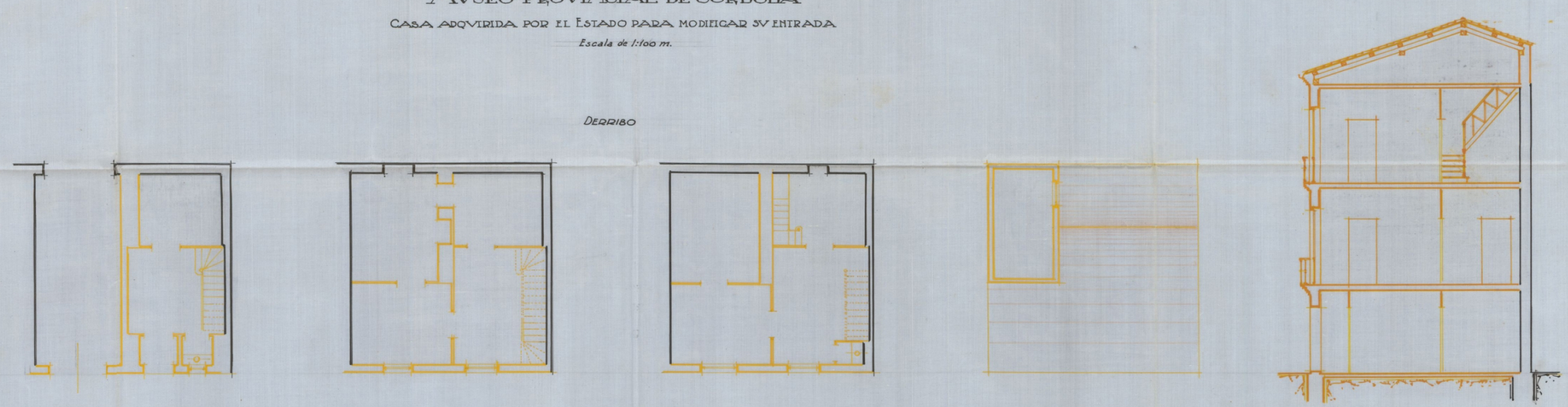

OBRA NVEVA
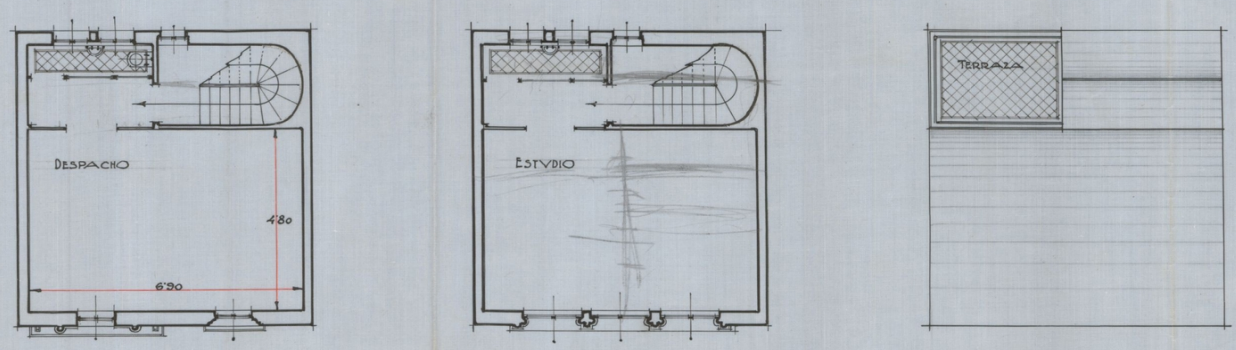

SEQVINOA

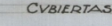

MADDID TMREO DC /926

EL AROVIRECTO

Staviededunga/

Fig. 3: Proyecto para el derribo y obra nueva de la casa n. 3. En amarillo se detallan los paramentos

derribados y en negro la obra nueva. Proyecto y presupuesto de demolición y reconstrucción de

la casa contigua al Museo Provincial de Bellas Artes de Córdoba. 01/03/1926.

MECD, AGA, IDD (05)014.002, caja 31/4954 
firma una recreación de lo que se pretendía que fuese el acabado final mediante una comparativa con lo ya existente ${ }^{29}$.

Este muro contaba con tres zonas claramente diferenciadas, que se especifican en el plano del proyecto de marzo de 1926 (Fig. 4): la primera, -la "parte existente" - corresponde al paramento exterior del antiguo Hospital de la Caridad, donde se encuentra el pórtico medieval de fábrica de piedra precedido por una reja colocada durante la restauración de Velázquez Bosco ${ }^{30}$; la segunda, -el "paramento nuevo" - se trata de un lienzo de pared liso, sin ningún vano, enfoscado y revocado con cal, solo alterado por la placa que conmemoraba la cita cervantina de este espacio. Correspondía al muro exterior de la iglesia del antiguo Hospital y en este momento funcionaba como sala del Museo Provincial ${ }^{31}$; y por último, la tercera - la "parte nueva" - corresponde a los números 1 y 3 de la plaza, que contaban con dos pórticos sencillos enlucidos. El primero de ellos es el de acceso al Museo que ya hemos comentado, y el segundo es el perteneciente a la vivienda. Cinco huecos más completaban la fachada, una pequeña ventana en la planta baja, una ventana y un balcón en la planta principal, y dos balcones en la segunda planta ${ }^{32}$.

Es importante hacer referencia a las cubiertas ya que al igual que la fachada iban a ser intervenidas. Estas se presentaban con características y materiales similares, con una armadura de madera y cubiertas con teja árabe.

29 Archivo Municipal de Córdoba (en adelante AMCO). c. 361, leg. 35. Obras particulares. Expediente relativo a las de reforma de la fachada de la casa n. 1 Plaza del Potro solicitada por D. Enrique Romero de Torres, director del Museo Provincial de Bellas Artes. Firmado por Carlos Sáez de Santamaría. 1928.

30 LÓPEZ RODRÍGUEZ, J. R.: op. cit., pp. 154-155.

31 La sala a la que estamos haciendo referencia es la actual Sala IV dedicada al Arte barroco cordobés en el Museo de Bellas Artes de Córdoba.

32 AGA. 31/4954. Proyecto y presupuesto de demolición y reconstrucción. op. cit.
La solución que daba el arquitecto para terminar con esta variedad de acabados fue la de reproducir el lenguaje de la "parte existente" en el resto de paramentos. Para ello, como vemos en el croquis que acompaña el proyecto, se realiza una copia de los elementos arquitectónicos, decorativos y de los materiales, "persiguiendo una mayor unidad entre lo existente y lo proyectado" ${ }^{33}$ (Fig. 5). Siguiendo este criterio, el tramo central requería una mínima intervención de eliminación del enfoscado de cal que dejara a la vista el muro de sillares de piedra; pero el tercer tramo demandaba una intervención integral de gran envergadura.

Continuando, el diseño creado para la "parte nueva" creaba una fachada historicista que armonizaba estéticamente con al antiguo pórtico. Para ello, por la imposibilidad de Francisco Javier Luque de acceder a la documentación y al proyecto original del desaparecido Hospital de la Caridad, se optó por recurrir a un sistema de $\operatorname{copia}^{34}$ de los elementos constructivos y decorativos usados en la arquitectura contemporánea al edificio medieval repartida por la ciudad. Es decir, hablamos de búsqueda de "inspiración" - término que emplea el proyecto- en las fachadas y portadas de la casa del Marqués de la Fuensanta del Valle, del Hospital de Agudos, de la iglesia de San Pedro de Alcántara y, principalmente, en el pórtico del Museo restaurado, con el que se pretendía establecer una rima estilística ${ }^{35}$
33 lbídem.

34 La copia de los elementos constructivos y decorativos consistía en la realización de unos modelos en yeso, siguiendo los referentes históricos, para luego traspasarlo a la piedra.

35 AGA. 31/4954. op. cit. 


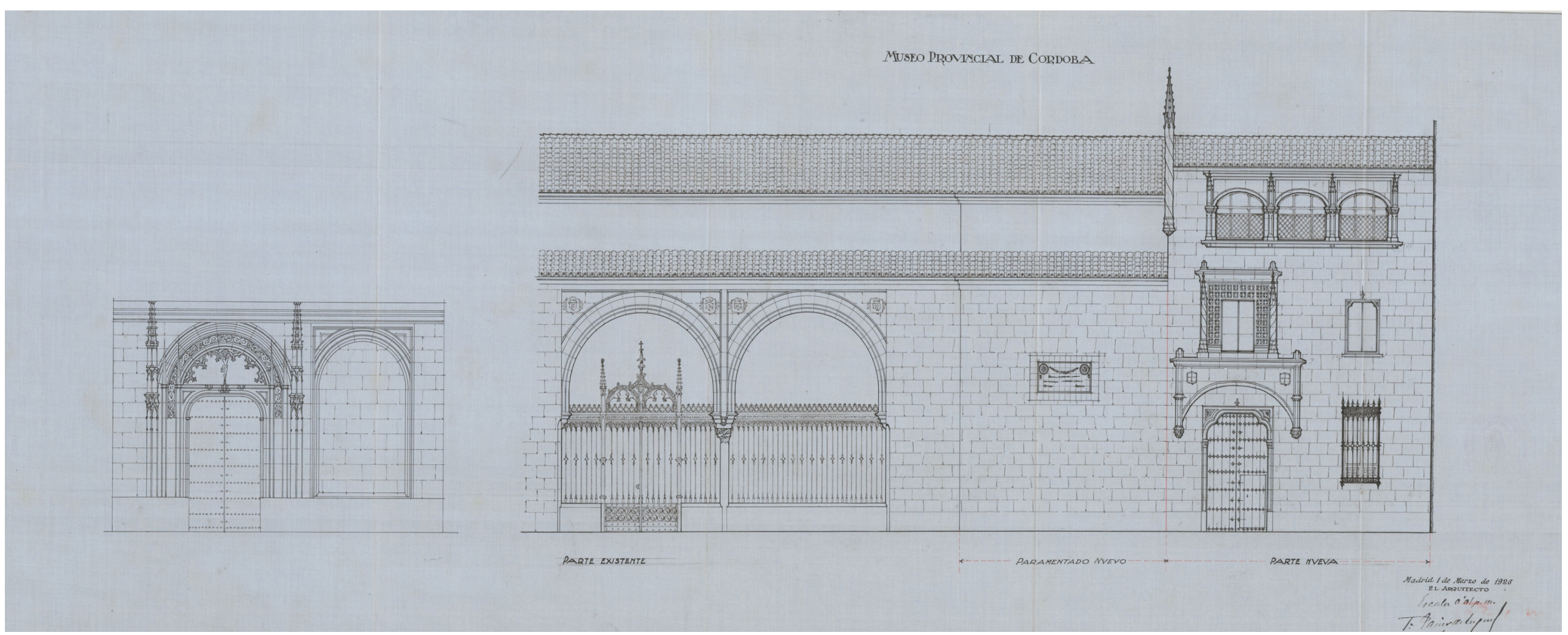

Fig. 4: Estudio para el diseño de la nueva fachada este de la plaza del Potro.

Proyecto y presupuesto de demolición y reconstrucción de la casa contigua al Museo Provincial

de Bellas Artes de Córdoba. 01/03/1926. MECD, AGA, IDD (05)014.002, caja 31/4954

Para cumplir con los objetivos de la intervención, el arquitecto propone cubrir los tramos de fachada del "paramento nuevo" y de la "parte nueva con sillería con espesor medio reducido a lo necesario" ${ }^{36}$. De este modo, la unidad quedaría reforzada con la selección de los materiales, con arreglo a su destino final, empleando para toda la fachada exterior sillería y fábrica de ladrillo. En el tramo nuevo se plantea una modificación estética general del muro que incide en el enmarcado de los vanos; pero también funcional,

36 Ibídem. ya que la puerta de acceso a la casa número 3 se transformaría en una ventana y los dos balcones de la segunda planta se convertirían en tres ventanas enfiladas.

Finalmente, el proyecto fue aprobado por Real Decreto de 24 de junio de 1927 del Ministerio de la Instrucción Pública y Bellas Artes ante Consejo de Ministros ${ }^{37}$. La adjudicación definitiva de las obras se realizó mediante la

37 Gaceta de Madrid. n. 175, 24 de junio de 1927, p. 1749. 


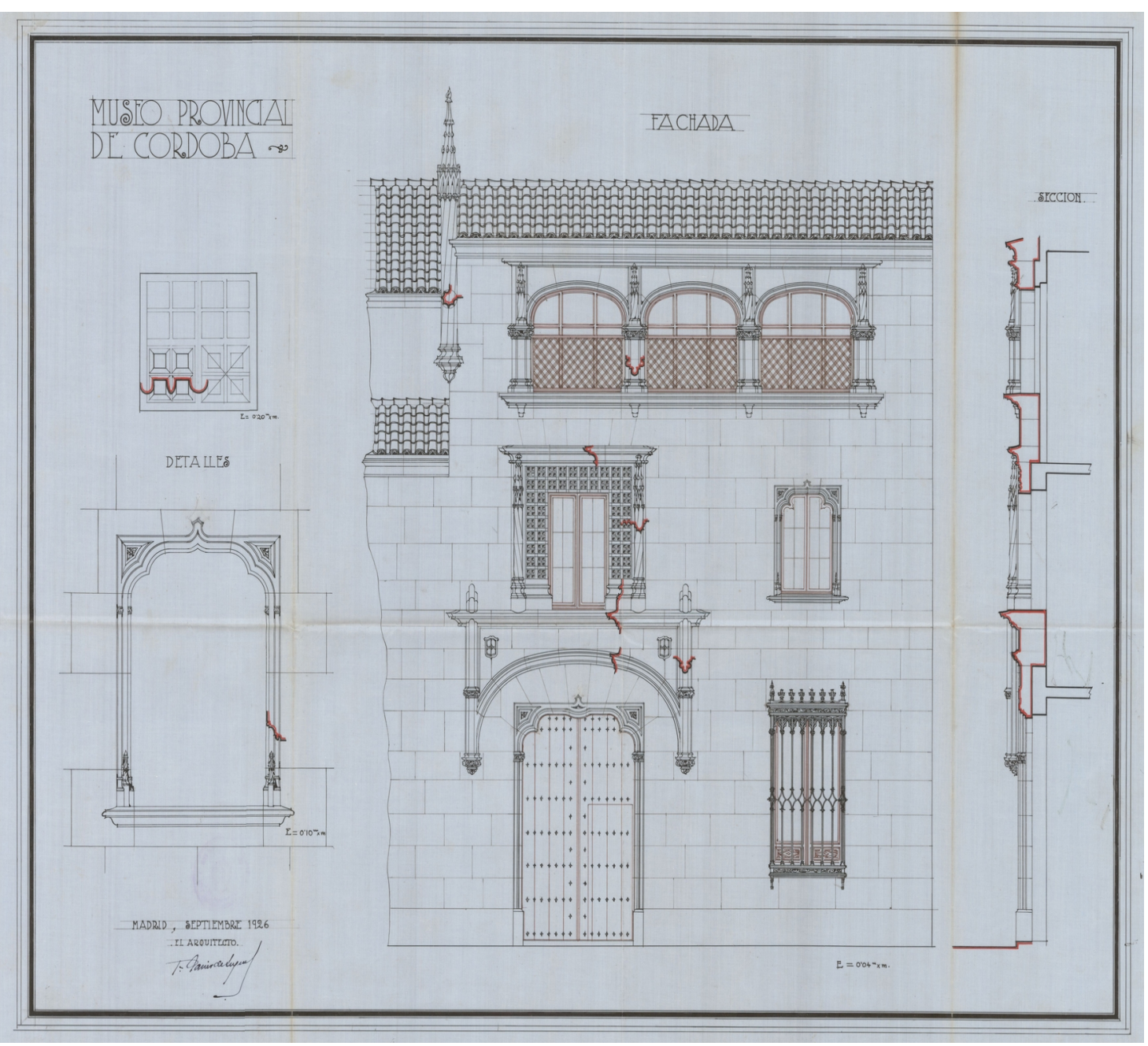

Fig. 5: Estudio/croquis para la decoración de la nueva fachada en estilo. Proyecto y presupuesto de demolición y reconstrucción de la casa contigua al Museo Provincial de Bellas Artes de Córdoba. 01/03/1926. MECD, AGA, IDD (05)014.002, caja 31/4954.
Real Orden de 12 de junio de 1928 al contratista don Antonio Rojas Romero ${ }^{38}$. Pero el desarrollo de los trabajos sufrió una serie de retrasos que provocó la rescisión de la contrata en noviembre de 1929, tras varias prórrogas solicitadas por el arquitecto ${ }^{39}$. Asimismo, se solicita la recepción provisional de las obras por Real Orden de 19 de diciembre de 1930 a José Rodríguez Cano, representante del Ministerio como arquitecto conservador de monumentos, a Enrique Romero de Torres, como director del Museo, al delegado de Hacienda de la provincia de Córdoba, y a Antonio Rojas Romero, contratista de las obras; pero los trabajos no habían avanzado desde la primera prórroga y, por tanto, se vieron en la tesitura de tener que conceder al contratista un nuevo plazo de seis meses ${ }^{40}$.

Más adelante, el 15 de agosto de 1931, Antonio Rojas emite una carta a la Dirección General de Bellas Artes informando de la finalización de las obras, solicitando su verificación por parte de la inspección ${ }^{41}$. Efectivamente estas se hallaban concluidas, situación que produjo que se procediera a la liquidación ${ }^{42}$ del total del presupuesto tras la aprobación

38 Gaceta de Madrid. n. 164, 12 de junio de 1928, p. 1461. Real Orden elevando a definitivo la adjudicación provisional de la contrata de las obras de reconstrucción, acceso y complemento de la fachada del Museo Provincial de Bellas Artes de Córdoba.

39 AGA. 31/4353. Memoria relativa a la liquidación final de las obras de reconstrucción, acceso y complemento de la fachada del Museo Provincial de Bellas Artes de Córdoba, 14 de diciembre de 1931; y PALENCIA CEREZO, J Mạ: op. cit., 2011, p. 33.

40 AGA. 31/4353. Ibídem; y AMBACO. c. 18, leg. 61. Actas del Patronato del Museo Provincial de Bellas Artes de Córdoba (en adelante APMPBACO). 10 de marzo de 1931.

41 AMBACO. c. 18, leg. 61. APMPBACO. 10 de septiembre de 1931.

42 La liquidación de las obras consistió en una valoración comparativa del presupuesto inicial aportado en la memoria del proyecto, con el resultado y los costes de las obras ejecutadas. AGA. 31/4353. Informe de la Dirección General de Bellas Artes que remite a la Junta Facultativa de Construcciones Civiles dando cuenta de la liquidación final de las obras de reconstrucción, acceso y complemento de la fachada del Museo Provincial de Bellas Artes de Córdoba. 25 de enero de 1932; y AGA. 31/4353. Acta de la recepción 
por parte del Ministerio de la instrucción pública el 12 de agosto del siguiente año, tal y como se recoge en el acta de la reunión del Patronato del Museo Provincial de Bellas Artes celebrada el 6 de octubre de $1932{ }^{43} \mathrm{y}$ la Orden de la Dirección General de Bellas Artes, de 27 de septiembre ${ }^{44}$, autorizando la recepción definitiva de las obras, que tuvo lugar el 9 de diciembre de $1932^{45}$. (Fig. 6)

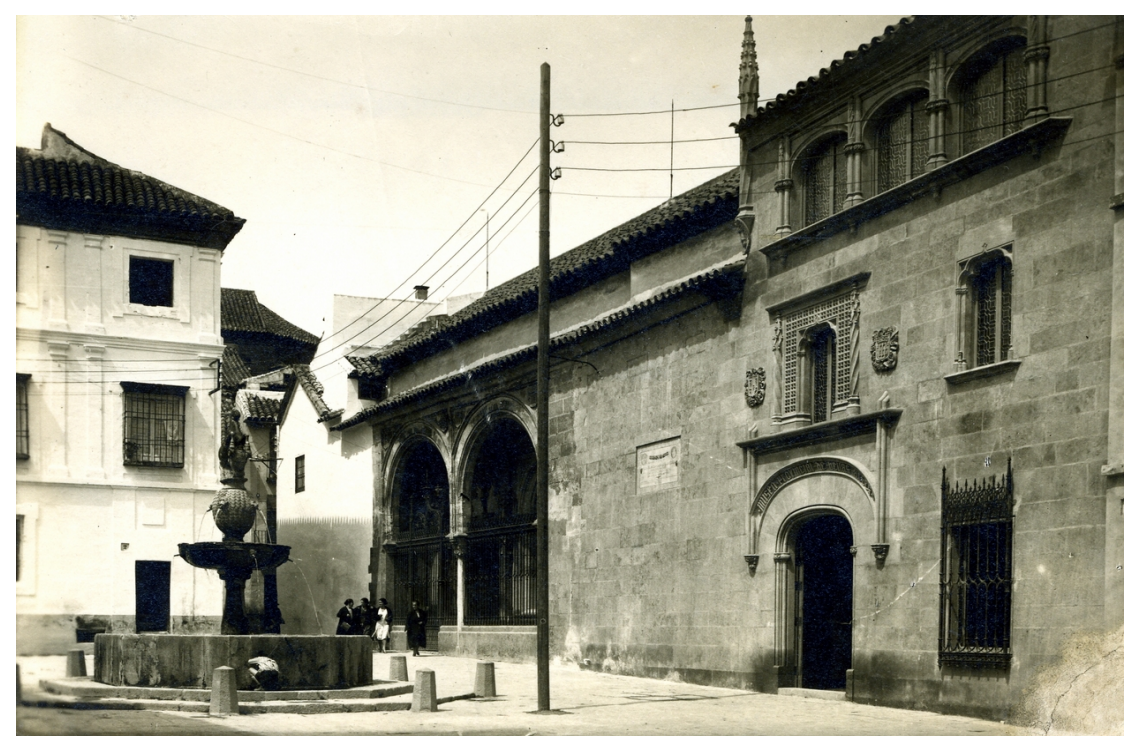

Fig. 6: Vista de la fachada del Museo Provincial de Bellas Artes tras la finalización de las obras de reconstrucción, acceso y complemento de la fachada realizadas por Francisco Javier Luque, ca. 1932. AHPCO. FFRT. F2285. Colección de la Junta de Andalucía.

definitiva de las obras de reconstrucción, acceso y complemento de la fachada del Museo Provincial de Bellas Artes de Córdoba. 28 de octubre de 1932.

43 AMBACO. c. 18, leg. 61. APMPBACO. 6 de octubre de 1932.

44 AGA. 31/4353. Duplicado remitido a Francisco Javier Luque del Acta de la recepción definitiva de las obras de reconstrucción, acceso y complemento de la fachada del Museo Provincial de Bellas Artes de Córdoba. 28 de octubre de 1932.

45 AMBACO. c. 18, leg. 61. APMPBACO. 13 de febrero de 1933.

\subsubsection{El proyecto definitivo: la incorporación de la casa número 5}

Como venimos exponiendo, la obra que se había realizado en la fachada del Museo Provincial de Bellas Artes de Córdoba traía aparejada la creación de nuevos espacios mediante la inclusión y adaptación de la casa n. 3 al conjunto museístico. Pero en 1926, cuando se inician los trabajos de demolición y reconstrucción en la finca anexionada, aún quedaba muy lejos la idea de crear un espacio expositivo que acogiera la colección Romero de Torres. Desde esta fecha hasta la entrega definitiva de las obras en 1932 las necesidades de la institución habían cambiado considerablemente, esto hace que la intervención de Francisco Javier Luque quedase insuficiente.

En un principio, con la casa n. 3 bastaba para dar cabida a los espacios que demandaba el director del Museo, pero con la muerte sobrevenida de Julio Romero y la donación de su obra ${ }^{46}$, se habilita provisionalmente el pabellón ocupado en este momento por la Real Academia de Córdoba. Tres fueron las habitaciones disponibles en este local ${ }^{47}$ para exponer toda la colección: una en la planta baja y dos en la superior. A lo que hay que añadir la zona de la escalera y un pequeño almacén. En estas, salvo alguna intervención de carácter escenográfico, no se produjo cambio alguno ni en su

46 No se ha encontrado constancia documental del número exacto de obras que formaron la primitiva colección del Museo Julio Romero de Torres, pero sí podemos establecer una aproximación y el origen de su procedencia. Por un lado, el grueso de la colección lo formaban 29 lienzos procedentes de la sala dedicada al pintor en la Casa de Córdoba de la Exposición Iberoamericana de Sevilla de 1929. A esto habría que sumar el "Busto de Julio Romero de Torres" realizado por Mariano Benlliure, y algunos cuadros más más y los enseres y objetos personales del pintor que se encontraban repartidos entre la casa familiar de Córdoba y el taller madrileño de Julio de la calle Pelayo.

47 Debemos recordar que las obras de reconstrucción, acceso y complemento de la fachada del Museo Provincial de Bellas Artes de Córdoba aún estaban sin entregar, y que este espacio que ocupa el primer Museo, el que deja la Academia, será intervenido con posterioridad. 
distribución ni en su estructura. Se distinguen dos propuestas de diseño en base a la forma y contenido de las museografías: una, que sigue una presentación lineal puramente contemplativa y estética; y otra, basada en el concepto de la recreación de ambientes. Todas las obras se disponían en la sala rellenando todo el espacio ocupando varias alturas sobre paredes cubiertas por telas Fortuny reutilizadas de la exposición sevillana, creando una sensación de abigarramiento visual.

Las nuevas salas expositivas se inauguraron el 23 de noviembre de 1931 y desde estos primeros momentos, ya quedó evidenciada la marcada estrechez e insuficiencia del local empleado para tal fin. El espacio no preveía el crecimiento de la colección y presentaba unas deficientes condiciones para aplicar los criterios y sistemas museográficos que se venían imponiendo en aquel momento en otras instituciones museísticas de similares características, a saber, los relativos a la circulación y seguridad de los visitantes, contemplación de las obras o zonas de almacén.

Ante esta precariedad que clamaba una nueva intervención, nos encontramos que aún no se habían entregado las obras iniciadas en 1926. $\mathrm{Y}$, a pesar de lo desfavorable del contexto, ya se estaba planteando la necesidad de adquirir una nueva finca para poder expandir el Museo ${ }^{48}$. A este tenor, el arquitecto remitió al Ministerio de la Instrucción Pública y Bellas Artes un proyecto de ampliación en el Museo Provincial de Bellas Artes de Córdoba, con fecha de 3 de diciembre de $1931^{49}$.

La nueva propuesta estaba justificada por la necesidad de instalar los cuadros y enseres de Julio en un espacio digno, así como de corregir la

48 AMBACO. c. 18, leg. 61. APMPBACO. 6 de octubre de 1932.

49 AGA. 31/4954. Proyecto de obras de ampliación en el Museo Provincial de Bellas Artes de Córdoba. Memoria. 3 de diciembre de 1931. estrechez y las deficiencias museográficas evidenciadas en la inauguración. Con esto queda patente que la compra de la casa número 3 solo supuso, prácticamente, una intervención estética cuya repercusión solo afectó a la fachada exterior y al urbanismo de la Plaza del Potro, pero quedó muy lejos de resolver las carencias funcionales.

En este contexto, llegamos a 1934 y las carencias detalladas en las salas del Museo Julio Romero de Torres aún no se habían solventado. Es por ello que en este mismo año Enrique Romero de Torres inicia las gestiones para la compra por parte del Estado de una nueva finca que vendría a ampliar el nuevo Museo. Tras varias idas y venidas a Madrid, en la sesión del Patronato del Museo Provincial celebrada el 10 de mayo de 1934, Enrique, como director de la institución, informa "del feliz éxito de sus laboriosas gestiones para que el Estado adquiriera la casa número 5 de la plaza del Potro, con el objeto de ampliar el 'Museo Julio Romero de Torres'”50.

El nuevo inmueble lindaba hacia el sur con la ya totalmente inserta en el conjunto casa n. 3. La compra, de la misma manera que ocurriera en 1924, fue realizada por parte del Estado, siendo Enrique Romero el firmante del contrato, como representación del Ministerio en calidad de director del Museo, con fecha de 4 de diciembre de $1934^{51}$. Con esta adquisición se sumarían un total de 102,71 metros cuadrados a la superficie del Museo Provincial, destinándose de manera específica a ampliar y dotar de nuevas salas al Museo Julio Romero de Torres ${ }^{52}$.

50 AMBACO. c. 18, leg. 61. APMPBACO. 10 de mayo de 1935.

51 Archivo Histórico Provincial de Córdoba (en adelante AHPC). c. 36. leg. 20. Museo Julio Romero de Torres. Documentos de gestión. Acta notal del Contrato de compra - venta de la casa n. 5 de la Plaza del Potro otorgada por don Enrique Fuentes Guerras, como mandatario de don Enrique Fuentes Peña a favor del Estado. 4 de diciembre de 1934; y PALENCIA CEREZO, J Mạ: op. cit., p. 34.

52 AMBACO. c. 1, leg. 1. exp. 12. 


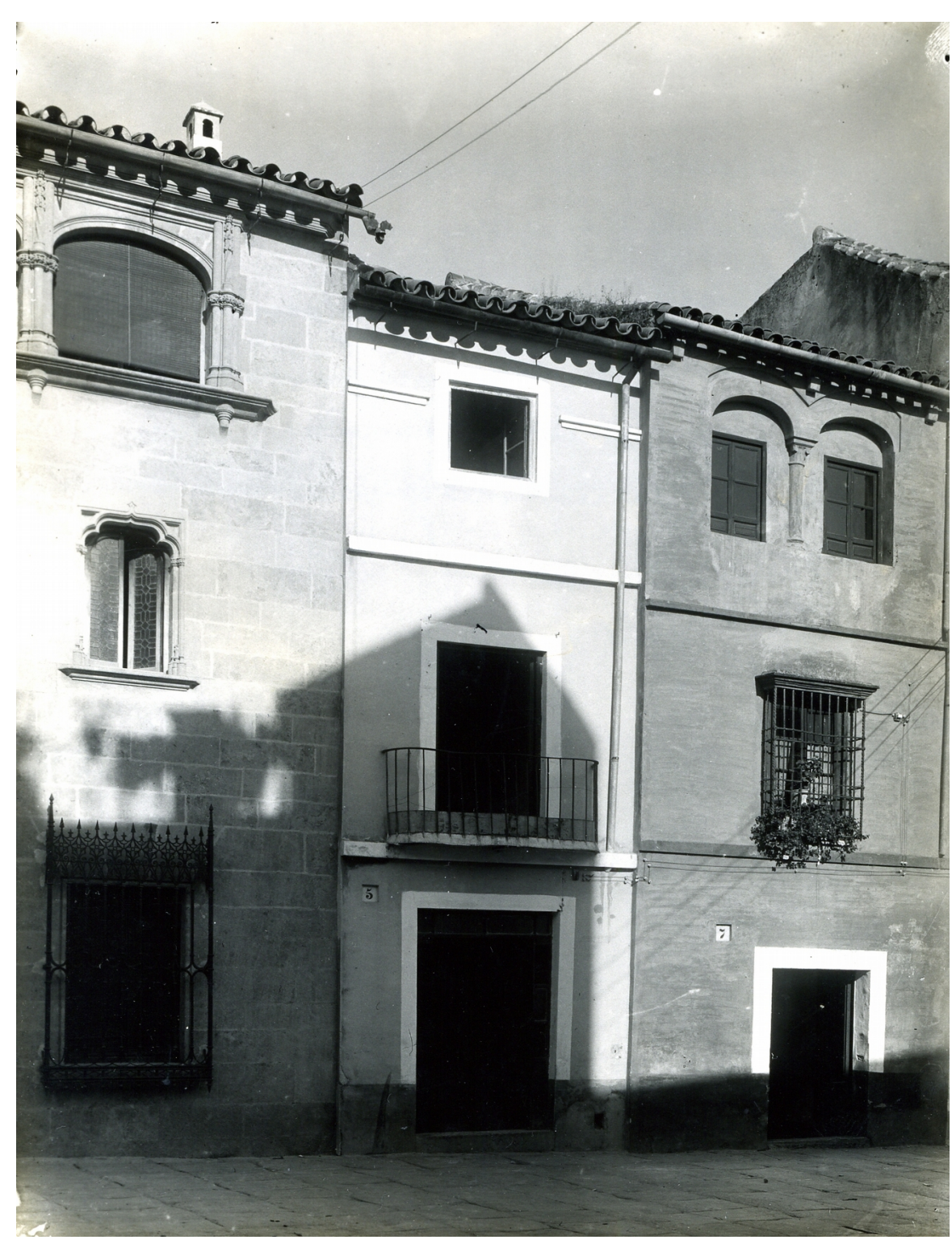

Fig. 7: Detalle del lado este de la plaza del Potro con la fachada de la casa número 5 contigua al Museo sin intervenir. ca. 1934. AHPCO. FFRT. F2282. Colección de la Junta de Andalucía.
La intención del Patronato del Museo Provincial de Bellas Artes era que las obras se iniciasen a la mayor brevedad posible ${ }^{53}$. Así, el Ministerio de la Instrucción Pública y el Patronato vuelven a contar con el arquitecto Francisco Javier Luque para la redacción de un nuevo proyecto para adecuar el espacio de la vivienda comprada al pabellón y a las nuevas dependencias resultantes de la rehabilitación de la casa $n$. 3, fusionando las tres fincas en un solo edificio, y por consiguiente, dando lugar a una configuración espacial nueva. En base a estos criterios, se redactaron varios proyectos que venían a dividir en diferentes fases la intervención global del conjunto: el primero de ellos, aprobado el 19 de febrero de 1935, de "Ampliación del Museo 'Julio Romero de Torres"' ${ }^{54}$; y el segundo, con fecha de 12 de julio de 1935, de "Obras complementarias a las de ampliación del Museo 'Julio Romero de Torres' en Córdoba”, que completaba lo proyectado meses antes en el primer texto ${ }^{55}$. Posteriormente, en marzo de 1936, se solicitará al mismo arquitecto una nueva memoria, en esta ocasión para las "Obras necesarias para la decoración y complemento de las tres salas que para la ampliación del Pabellón denominado 'Museo Julio Romero de Torres'”56.

53 Muestra de ello son las notas que remite el Patronato a finales del mes de diciembre de 1934 a Antonio Aranda, -inquilino hasta el momento de la casa adquiridasolicitándole que sea vaciado todo el inmueble para poder iniciar los trabajos pertinentes. AMBACO. c. 1, leg. 1. exp. 12. Nota remitida por director del Museo Provincial de Bellas Artes en nombre del Patronato del Museo a don Antonio Aranda para que desaloje la casa n. 5 de la Plaza del Potro, 20 de diciembre de 1934.

54 AGA. 31/4343. Informe favorable remitido por la Dirección General de Bellas Artes del Ministerio de la Instrucción Pública y Bellas Artes al Director General de Bellas Artes, y su traslado a las partes interesadas, del proyecto de Ampliación del Museo Julio Romero de Torres en Córdoba, redactado por el arquitecto Francisco Javier Luque. 19 de febrero de 1935.

55 AGA. 31/4954. Proyecto y presupuesto de obras... op. cit.

56 AMBACO. c. 1, leg. 1. exp. 12. Oficio remitido por el Director General de Bellas Artes del Ministerio de la instrucción Pública y Bellas Artes al arquitecto Francisco Javier Luque y al presidente del Patronato del Museo Provincial de Bellas Artes de Córdoba. 17 de 
El primer proyecto firmado por Luque estaba justificado, a grandes rasgos, por el aumento de la colección ${ }^{57}$. De este modo, el espacio del pabellón inicial se planteó como una solución provisional, con carácter temporal, que no permitía el crecimiento de la colección expuesta. Es llamativo que la demanda de ampliar las salas viniera dada por el aumento de la colección, cuando desde un principio ya era una carencia patente.

Fuera por una necesidad de espacio inicial o sobrevenida, el proyecto de Luque planteaba un acrecentamiento considerable de los espacios al añadir la pequeña casa recién adquirida por el Estado. Las actuaciones previstas contemplaban una intervención marcada por dos fases: la primera, consistente en el derribo total de la finca; y la segunda, por la construcción de un nuevo inmueble.

Contrariamente a la situación que presentaba la primera casa, cuyo estado de conservación era óptimo, la número 5 tenía una construcción bastante deficiente, a lo que hay que añadir una distribución espacial interna de la que poco se podía aprovechar. Es por ello que se decide demolerla prácticamente en su totalidad, "salvo alguna sillería, la teja, y los peldaños de una escalera de servicio" ${ }^{58}$, reutilizados en la nueva construcción.

La segunda parte del proyecto, consistía en levantar de nueva planta un edificio que se acomodase a la estética e instalaciones, tanto en el interior

marzo de 1936

57 La justificación del proyecto se plantea de la siguiente forma: "habiendo aumentado los fondos del Museo gracias a la generosidad de la familia del malogrado artista se impone la ampliación de los locales de aquel, para lo cual se ha adquirido una pequeña casa contigua [...]". AGA. 31/4343. Informe de la Dirección General de Bellas Artes del Ministerio de la Instrucción Pública y Bellas Artes a la Junta Facultativa sobre el Proyecto de obras de ampliación del Museo Julio Romero de Torres de la ciudad de Córdoba. 16 de enero de 1935.

58 Ibídem. como en el exterior del conjunto del Museo Provincial, siguiendo, como en la intervención precedente, el guion visual del antiguo Hospital de la Caridad. Asimismo, la estructura, alzado y disposición tenían que anexionarse con las dependencias derivadas de la casa n. 3 y del primitivo pabellón ${ }^{59}$. De este modo, se buscaba crear un espacio y alzado totalmente unificado en el que no quedase constancia alguna del cosido de fincas ${ }^{60}$.

En definitiva, con la nueva intervención se ganaban metros cuadrados, permitiendo una mejora en la exposición de las obras. Así, la fachada exterior quedaba ampliada hacia su derecha siguiendo el mismo criterio de recreación historicista llevado con anterioridad ${ }^{61}$. De igual manera, se introducen los usos a los que se iban a destinar las nuevas instalaciones, detallándose las zonas comunes, de servicios y de administración. Pero, contrariamente, no se dan muchas precisiones sobre los nuevos espacios previstos para uso expositivo, a pesar de que la implementación de estas zonas era la justificación principal del proyecto. Solo se menciona un salón en la planta baja y dos en la superior.

El proyecto fue aprobado por la Dirección General de Bellas Artes del Ministerio de la Instrucción Pública y de Bellas Artes el 19

59 AGA. 31/4954. Proyecto y presupuesto de obras complementarias... op. cit.

60 Esta idea queda detalla en la memoria del proyecto en los siguientes términos: “[...] construcción en el solar resultante de la ampliación del Museo, repitiendo en la fachada los mismos elementos de composición que constituyen la actual. En nuevo cuerpo de edificio constará de dos plantas, como el contiguo, destinándose la planta baja a vestíbulo de ingreso, portería, un despacho, un Salón para Museo y un almacén y la planta alta a dos Salones y un depósito de cuadros". AGA. 31/4343. Informe de la Dirección General... op. cit.

61 En este momento es cuando se termina de configurar la pared Este de la Plaza del Potro, aspecto que hoy presentan el Museo de Bellas Artes de Córdoba y el Museo de Julio Romero de Torres. 
febrero de $1935^{62}$, tras el informe favorable emitido por la Junta Facultativa, en el que solamente se apostillaba "que las cubiertas proyectadas que llevarán forma y correas de hierro y el resto de madera convendría sustituirlas por otras formadas de parecillos de hierro y forjado de rasilla para asegurar su incombustibilidad" ${ }^{63}$, proponiendo, por tanto, la eliminación de la madera como material de fácil combustión para apostar por una estructura ignífuga. Esta pequeña rectificación da cuenta del interés de las autoridades por velar por la seguridad de las colecciones, marcando criterios para la selección de los materiales constructivos de los edificios de museos. En este caso, se propone una selección de elementos que confieran una mayor resistencia al inmueble a situaciones conflictivas como un posible incendio, teniendo, por tanto, en cuenta el uso museal con el que se va a dotar.

En esta línea, la generalización del empleo de sistemas ignífugos como medida de seguridad viene dado por las recomendaciones que la Oficina Internacional de Museos de la Sociedad de Naciones da en sus reuniones. Así, y extrapolándonos al contexto internacional, en 1934 se celebra en Madrid la Conferencia Internacional de Museos, con el título Muséographie: architecture et aménagement des musées d'art. En el capítulo I del tomo I, - Le programme architectural du musée. Principes généraux - se hacía una reflexión sobre la construcción de edificios destinados a museos y los materiales que debían ser empleados para ello, mencionando la conveniencia de la elección de aquellos que fueran incombustibles o ignífugos. ${ }^{64}$

\section{Ibídem.}

63 AGA. 31/4343. Comunicación de la Dirección General de Bellas Artes del Ministerio de la Instrucción Pública y Bellas Artes al arquitecto Francisco Javier Luque sobre el informe favorable al proyecto de Ampliación del Museo Julio Romero de Torres. 25 de enero de 1935.

64 Estas recomendaciones quedan expresadas en los siguientes términos en las actas de la
Continuando con los proyectos presentados para la ampliación del Museo que nos ocupa, tenemos que detallar las cuestiones planteadas en el texto que Luque presenta en julio de 1935 para completar lo proyectado y aprobado en la primera memoria. Con el título de "Obras complementarias de las de ampliación del Museo 'Julio Romero de Torres'”, el arquitecto traza un análisis más detallado de las modificaciones ya previstas para el solar de la casa n. 5 en el primer proyecto, e introduce unos añadidos que completarían el fortalecimiento del mismo, consistentes en la mejora de las comunicaciones entre las diferentes alturas del inmueble mediante la ampliación de la escalera del público; y la construcción de un torreón que fuera visible desde la fachada exterior. Todo esto queda expuesto en la memoria y en los planos adjuntos, estos últimos de vital importancia para entender el proyecto (Fig. 8).

conferencia: "El museo debe, por su construcción, no presentar riesgos de incendio. Los materiales deben ser especialmente seleccionados. No se deben usar paneles de madera barnizados o pintados, telas colgadas, así como suelos de parqué, los cuales, por otra parte, tienen la desventaja de generar fatiga al visitante. Se deben tomar precauciones contra los riesgos de cortocircuito. Las medidas adoptadas para la protección de los cortafuegos podrían usarse para los museos. Todos los materiales inflamables deben tratarse específicamente: la madera debe ser ignifuga, tratada mediante un proceso de oxigenación, por ejemplo. Por lo tanto, será necesario tratar asientos, ventanas, armarios y dibujos con elementos resistentes al fuego, siempre que el proceso no altere la apariencia de los objetos, todos los objetos de madera deben ser a prueba de fuego, para que lo protejan contra las llamas y evitar así que sea deformado por el calor y el derrumbe del edificio" (traducción libre de la autora del original en francés). AA. VV.: "Le programme architectural du musée. Principes généraux", Conférence Internationale d'Études. Muséographie. Architecture et aménagement des musées d'art, Madrid, Société des Nations. Office International des Musées, 28 de octubre al 4 de noviembre de 1934. París, 1935 (Granada, 2005 ed. facsímil), Cap. V., T. I., p. 34. AGA. 31/4954. Proyecto y presupuesto de obras complementarias a las de ampliación... op. cit. 


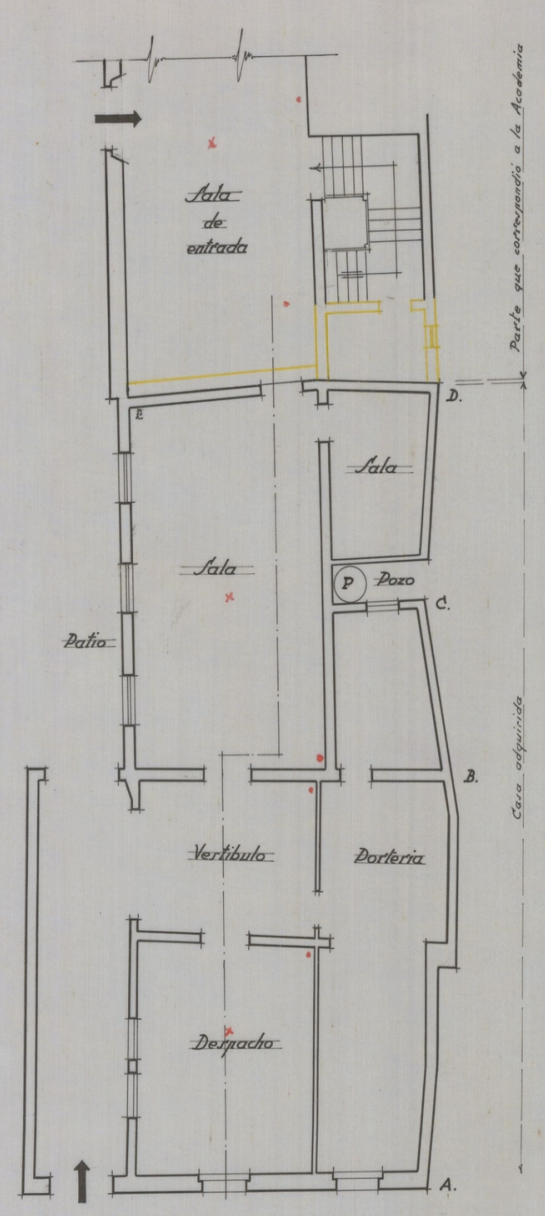

DLANTA BAJA

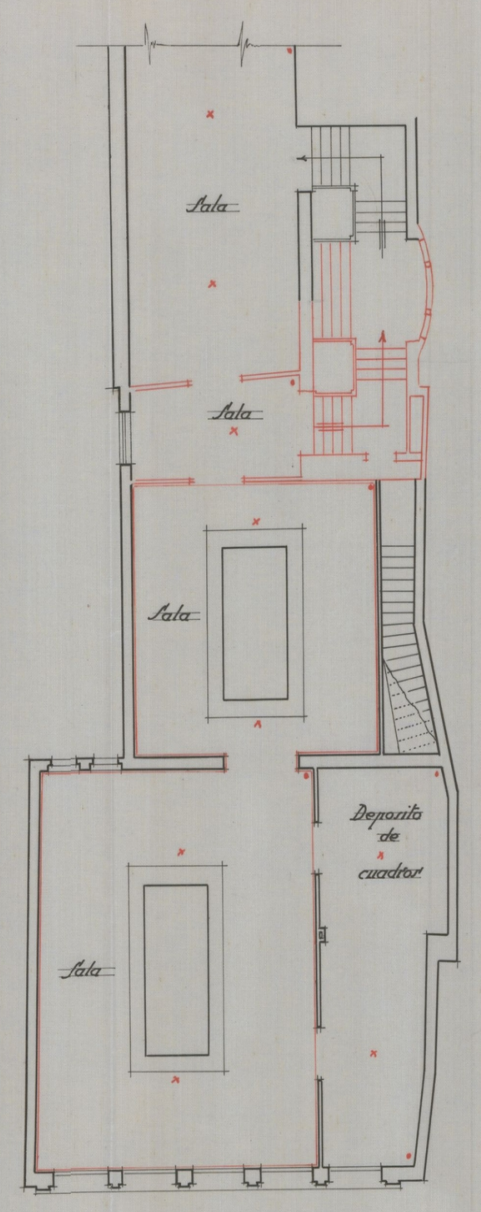

DLANTA PRAL.

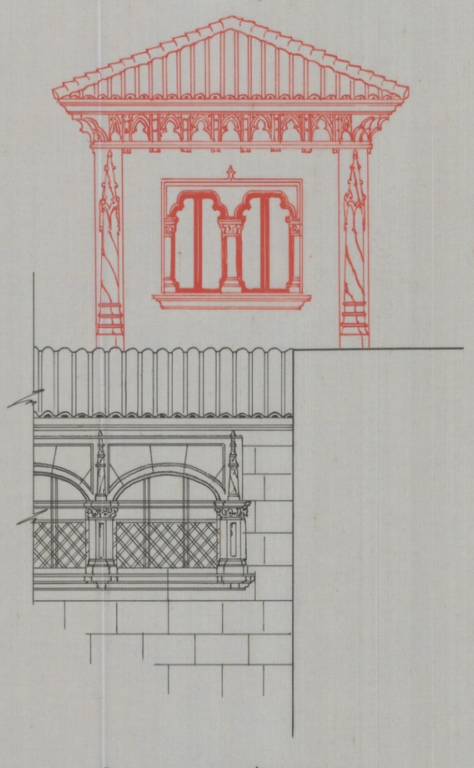

DETALLE DEL ALZADO

\section{Obras complementarias}

en el Museo

- Romero de Torres.-

IJICALA - 1:100

Fig. 8: Plano con las modificaciones previstas en las casas 3 y 5 y en el antiguo pabellón para

la creación de un edificio para el Museo Julio Romero de Torres. Proyecto y presu-

puesto de obras complementarias a las de ampliación del Museo Julio Romero

de Torres en Córdoba. 12/07/1935. MECD, AGA, IDD (05)014.002, caja 31/4954. 
Comenzados los trabajos, durante el momento de derribo de la finca n. 5 se encontraron con una serie de problemas vinculados a la estructura de la casa y a la medianera que lindaba con la siguiente propiedad $-\mathrm{n}$. 7 de la Plaza del Potro-, que el arquitecto detalla en la memoria y plano del proyecto $^{65}$. De igual modo, existían zonas de servidumbre compartidas con la casa contigua, como un pozo mancomunado ${ }^{66}$, -identificado en plano con la letra $\mathrm{P}-$, que obligaba a romper la unidad del espacio interior al tener que respetar esta zona en la planta baja. Aunque en el plano no queda recogido, esta irregularidad se solventó al llegar a un acuerdo con el propietario de la casa colindante para que cediera el uso del pozo al Museo $y$, poder así, trazar una medianera sin saltos $^{67}$.

La memoria prosigue indicando el derribo del muro que lindaba con las dependencias de la antigua Academia, -en plano señalado con las letras D-E- Esta medianera trajo, igualmente, varios inconvenientes, ya que presentaba un grosor muy considerable y la estructura del pabellón era muy deficiente al estar construida con madera podrida - como apostilla el arquitecto- y forjado de cascotes, materiales que debilitaban la estructura, haciendo inviable su reutilización en la nueva construcción. Por

65 El arquitecto explica estos problemas en la memoria del proyecto en base a las indicaciones graficas dadas en plano, de la siguiente forma: "1ㅇ-- De derribo: Toda pared al parecer medianera desde A a B y desde C a D no lo era; esta pared era perteneciente tan solo a la finca adquirida y al derribarla se vio que la casa contigua (que ya no era propiedad del Museo) se había servido de ella para cerramiento al ser construida la finca; [...] lo que precisaba llevar a efecto en toda la altura de la finca, así como construir esa pared colindante a su estabilidad y resistencia, pero sin consentir que dicha casa colindante entrase en esta pared por ninguno de sus puntos ni en la cantidad más insignificante". Ibídem.

66 El uso compartido de este pozo por las dos fincas no quedaba justificado, ya que en este momento todas las casas de Córdoba contaban con abastecimiento propio. Esto propició, según indica la memoria del proyecto, a que se llegara a un acuerdo con el propietario de la casa colindante para que cediera el uso del pozo al Museo.

67 AGA. 31/4954. Proyecto y presupuesto de obras complementarias... op. cit. ello se proyecta la sustitución de todas las medianeras por tabiquería para estructura, haciendo inviable su reutilización en la nueva construcción. Por los espacios destinados a salas del Museo, las cuales quedan bien señaladas en el plano por sus nombres. Asimismo, el derribo de la casa vieja exigía tener que equiparar los niveles de las plantas a los del edificio de la Academia68, para evitar los cambios de nivel y peldaños tan inadecuados en un espacio destinado al trasiego y deambular de visitantes.

Concluido el derribo de la casa n. 5, tras el verano de 1935 se inicia la construcción de nueva planta del edificio en el que finalmente tendría su sede el Museo Julio Romero de Torres de Córdoba, en base a las modificaciones aportadas en la segunda memoria del proyecto. La intervención comenzó con la ampliación de la caja de la escalera, permitida por la supresión del pozo antes referido, una de las zonas de tránsito más conflictivas que podemos encontrar en un museo. En un principio, en el pabellón antiguo, la conexión entre las dos alturas estaba planteada mediante una escalera de un solo ramal. Este espacio era muy estrecho y poco funcional para la cantidad de visitantes que deambulaban por ellas, por ello se propone un ensanchamiento del mismo. Como muestra el plano, al ampliar "el primer tramo de subida y dando desde la primera mesilla ${ }^{69}$ disposición perfectamente simétrica está evitada la dificultad del tránsito porque se consigue un ramal de ingreso y otro de salida" ${ }^{70}$,

68 En el proyecto nada se habla de la unión con la reforma realizada en la casa n. 3, pero entendemos que se sobreentiende su inclusión al formar ya parte esta finca del recinto del Museo. Igualmente, esta idea se sustenta cuando veamos más adelante cómo algunas de las salas del Museo Julio Romero de Torres se expanden hacia la fachada de la Plaza del Potro y, por tanto, entran en la primera finca adquirida.

69 La mesilla es el término empleado para referirse al rellano o porción horizontal en que termina un tramo de escalera.

70 En el plano aparece bien diferenciada la caja de la escalera, en negro para el tramo de un solo ramal proyectado en un primer momento, y en rojo para la modificación posterior que iba a permitir un doble ramal. AGA. 31/4954. Proyecto y presupuesto de 
aumentando de este modo considerablemente las dimensiones del rellano y facilitando la circulación.

Además, este segundo proyecto tuvo a bien incluir las observaciones realizadas por la Junta de Construcciones Civiles en lo referente a la inclusión de materiales ignífugos, concretamente en las armaduras que cubrían las nuevas salas, se aconsejaba que fueran de hierro. El último apartado del texto no se llegó a materializar por motivos presupuestarios. Nos referimos a la construcción de un torreón que remataba del edificio en el lado derecho de la fachada y que se vería desde la plaza ${ }^{71}$. Finalizados los trabajos, con los añadidos y modificaciones del segundo proyecto, las obras debieron estar entregadas al inicio del año $1936^{72}$, y el 24 mayo de ese mismo año se reabren al público las nuevas salas del Museo Julio Romero de Torres ${ }^{73}$.

Tal y como vemos en un proyecto relativo a diferentes obras en todo el conjunto, firmado por el arquitecto Rafael de la Hoz en $1942^{74}$, podemos

obras complementarias... op. cit.

71 Este elemento quedó reflejado en el plano, dibujado en rojo y siguiendo la estética que ya diseñara Francisco Javier Luque en la recreación en estilo para la fachada. Al igual que como ocurre con las bóvedas, este también se idea siguiendo los consejos de la Junta, incluyendo, por ello, una estructura de hierro. Pero finalmente no llegó a realizarse y no tenemos constancia del momento exacto en que se frustra su construcción. Ibídem.

72 No se han localizado las actas de entrega definitiva, pero sí noticas del Patronato del Museo dando cuenta en una sesión celebra el 21 de noviembre de 1935, de que, tras la inspección de los locales, lo proyectado estaba muy avanzado.

73 El Museo estuvo cerrado para efectuar los trabajos de mejora prácticamente 9 meses, desde agosto de 1935 hasta la fecha indicada.

74 AGA. 31/5515. Proyecto de sustitución del pavimento de madera de un salón por mármol, colocación de cancela de cristal y construcción de taller para reparación de cuadros. Museo de Bellas Artes y en el Museo Julio Romero de Torres. Rafael de la Hoz. 30 de julio de 1942. conocer con precisión el resultado final de la distribución del nuevo edificio (Figs. 9 y 10). Respecto al pabellón inicial del Museo Julio Romero de Torres se incrementa en tres salas el espacio expositivo y nuevas zonas de uso interno, distribuidas de la siguiente forma: la planta baja contaba con dos salones de exposición, uno de ellos perteneciente al antiguo pabellón y otro surgido tras el añadido de 1934. También cuenta con unas habitaciones destinadas a depósito de cuadros, un trastero y unas dependencias para uso de conserje, salidas de la intervención en la casa $n$. 3, cuyo uso estaría compartido con el Museo Provincial. La planta alta se amplía considerablemente, ya que al salón principal y a la pequeña salita preexistentes, se le suman dos nuevas, una salía de la vivienda $n$. 5 y otra de la n. 3, un pequeño trastero, un baño y la ampliación de la escalera con un segundo tramo.

Las cubiertas, son otra cuestión a tratar para terminar de definir el resultado final del edificio. Las salas superiores del antiguo pabellón estaban cubiertas por unas armaduras de madera y en el interior contaba con unas falsas bóvedas de yesería en las que se habían abierto unos pequeños lucernarios que permitían la iluminación del interior. Pero con la reforma de 1934 se eliminan estas techumbres, como ya hemos dicho, adaptándolo a los requerimientos de seguridad contra incendios impuestos por el contexto de la Oficina Internacional de Museos, abriendo nuevos lucernarios y ampliando los ya existentes para asegurar una iluminación cenital natural del interior de las salas, tal y como se detalla en el plano de Rafael de la Hoz.

Solo falta para concluir concretar la instalación de las obras en las salas. Así, en marzo de 1936, en una nota del Patronato remitida al Director General de Bellas Arte, se informa de que se ha solicitado a Francisco Javier Luque un presupuesto para "el decorado y complemento de las expresadas salas a fin de que puedan quedar expuestos en éstas, con el decoro que se 

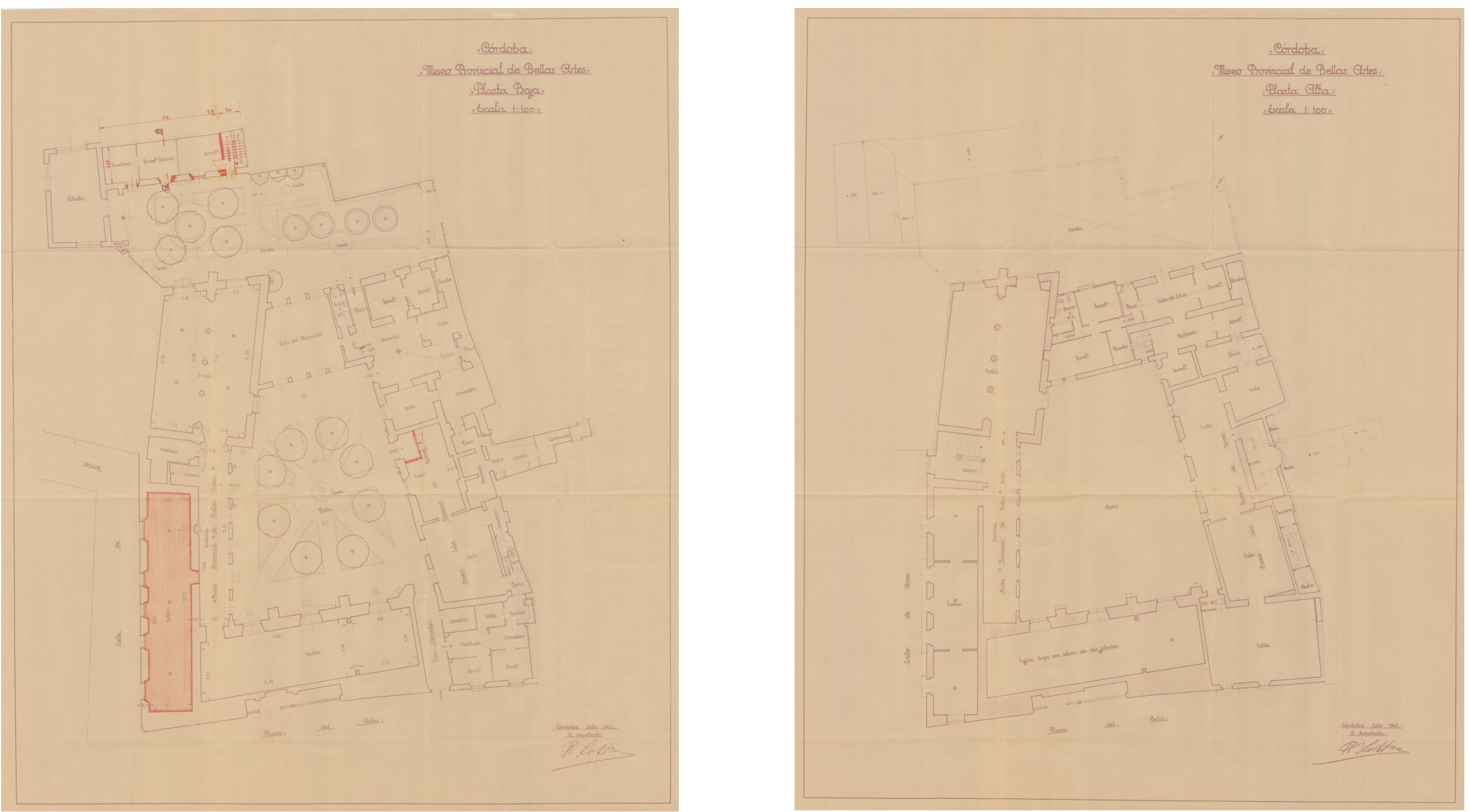

Figs. 9 y 10: Planos de las plantas baja y alta del conjunto museístico de la Plaza del Potro. En la esquina interior derecha se detalla la configuración espacial del Museo Julio Romero de Torres. Proyecto de sustitución del pavimento de madera de un salón por mármol, colocación de cancela de cristal y construcción de taller para reparación de cuadros. Museo de Bellas Artes y en el Museo Julio Romero de Torres. Rafael de la Hoz. 30/07/1942. MECD, AGA, IDD (05)014.002, caja 31/5515. 
merece, los notables cuadros del inmortal artista $[\ldots]^{\prime \prime 75}$, petición que hace suponer que el encargado del diseño museográfico correría a cargo del arquitecto, aunque suponemos que Enrique Romero de Torres y el hijo de Julio, Rafael Romero de Torres Pellicer, jugaron un papel activo en este.

La instalación y exposición de las obras de Julio Romero, mantuvo el diseño expositivo seguido en 1931, diferenciando entre espacios de recreación de ambientes y los de presentación lineal contemplativa de las obras. Pero también solventó las carencias del montaje inicial. La colección aumentó en una treintena piezas entre lienzos y enseres que ingresan gracias a donaciones, depósitos, cesiones y compras que gestiona la familia Romero de Torres $^{76}$, pero, como hemos comentado, también lo hicieron los metros lineales de exposición. Es por ello que la sensación de abigarramiento fue suprimida para dar a cada obra su espacio, permitiendo una contemplación individualizada de las mismas.

75 AMBACO. c. 1, leg. 1. exp. 12. Nota remitida por el Patronato del Museo Provincial de Bellas Artes en nombre del Patronato del Museo al Director General de Bellas Artes, informando de la solicitud de un presupuesto para la decoración de las nuevas salas del Museo Julio Romero de Torres. 10 de marzo de 1936.

76 Todos estos nuevos ingresos quedan recogidos y aprobados en las actas de las diferentes sesiones que celebra el Patronato del Museo Provincial de Bellas Arte desde 1933 hasta 1936.

\section{CONCLUSIONES}

Después de analizar los proyectos de obras realizadas en el Museo Provincial de Bellas Artes de Córdoba desde 1924 a 1936, comprobamos que durante algo más de una década el planteamiento de las actuaciones estuvo marcado, en cierto modo, por una constante adecuación del conjunto a necesidades sobrevenidas. Aquí se manifiesta la idea de que la arquitectura de museos es el soporte físico de la institución ${ }^{77}$ y debemos entenderla como un organismo vivo que no tiene otro cometido que el de adecuarse a las funciones museísticas.

Por otra parte, el museo se presenta como un elemento configurador del espacio urbano. Las transformaciones llevadas cabo en el conjunto museístico del Hospital de la Caridad son una muestra de ello. Vemos como la Plaza del Potro desde 1915 hasta 1936 ha ido cambiando su fisionomía al tiempo que ha ido enriqueciéndose culturalmente al añadir a su paisaje nuevas arquitecturas y un nuevo museo. Por ello, podemos afirmar que no se trató solo de la creación de una institución museística, sino que se dotó de una nueva imagen a la Plaza del Potro que vino a reforzar sus valores histórico-artísticos por los que se la declaró Monumento arquitectónico-artístico.

77 HERNÁNDEZ HERNÁNDEZ, F.: Manual de Museos. Madrid, Síntesis, 1994, p. 165. 


\section{BIBLIOGRAFÍA}

AA.VV.: La restauración de la fachada del antiguo Hospital de la Caridad. Museo de Bellas Artes de Córdoba. Sevilla, Junta de Andalucía, 2011.

: "Le programme architectural du musée. Principes généraux", Conférence Internationale d'Études. Muséographie. Architecture et aménagement des musées d'art, Madrid, Société des Nations. Office International des Musées, 28 de octubre al 4 de noviembre de 1934. París, 1935 (Granada, 2005 ed. facsímil), Cap. V., T. I.

BALDELLOU SANTOLARIA, M.: Ricardo Velázquez Bosco. Catálogo de exposición. Madrid, Ministerio de Cultura, Centro Nacional de Exposiciones, 1990.

BAZTÁN LACASA, C.: "Museos en monumentos. Una pequeña historia y treinta ideas", Revista de Museología, no 17 (Arquitecturas para la mirada). A.E.M. Madrid, junio 1999, pp. 25-31.

DESVALLÉES, A., y MAIRESSE, F. (dirs.): Conceptos claves de museología. París, Armand Colin, 2010.

GARCÍA RAMOS, Ma D.: “Consideraciones en torno a la definición tipológica del Museo Julio Romero de Torres de Córdoba", "Yngenio et arte": elogio, fama y fortuna de la memoria del artista. 2017 (En prensa).

HERNÁNDEZ HERNÁNDEZ, F.: Manual de Museos. Madrid, Síntesis, 1994.

LÓPEZ RODRÍGUEZ, J. R.: Historia de los museos de Andalucía. 1500-2000. Sevilla, Universidad de Sevilla, 2010.
LORENTE LORENTE, J. P.: Manual de historia de la Museología. Gijón, Trea, 2012.

MAIRESSE, F.: “¿Ha terminado la historia de la museología?”, ICOFOM Study Series, 35, 2006, pp. 91-104.

: Dictionnaire encyclopédique de muséologie. París, Armand Colin, 2002.

MONTANER, J. Mạ: Los museos de última generación. Barcelona, Gustavo Gili, 1986.

MUÑOZ COSME, A.: Los espacios de la mirada. Historia de la arquitectura de museos. Gijón, Trea, 2007. 